\title{
Medical aid in dying: What matters most?
}

\author{
Peter Tanuseputro MD MHSc
}

Cite as: CMAJ 2017 January 23;189:E99-100. doi: 10.1503/cmaj.161316

See also www.cmaj.ca/lookup/doi/10.1503/cmaj.160650

$\mathbf{W}$ ith the passing of Bill C-14, Canadians who are mentally competent adults suffering from a grievous and irremediable medical condition may now seek medical aid in dying. ${ }^{1}$ The policy has already resulted in ripples of controversy. For example, some large faith-based hospitals currently do not allow medical aid in dying on their premises, ${ }^{2}$ and a Canadian Medical Association survey of Canadian physicians found that $61 \%$ would refuse to provide this service and $14 \%$ were not sure if they would. ${ }^{3}$ In a linked paper, Trachtenberg and Manns ${ }^{4}$ explore a provocative observation that medical aid in dying will curtail, for some, the endof-life period that is associated with intensive and costly health care. They estimate the annual cost savings that might be associated with medical aid in dying in Canada to be between $\$ 34.7$ million and $\$ 138.8$ million. These potential cost savings, which are not trivial, should be considered in the context of the largely inadequate and haphazard delivery of palliative care across Canada. ${ }^{5}$ Despite some successful and exemplary palliative care programs, palliative care in Canada remains deficient; this is the reason that aggressive, institution-based and ultimately costly end-of-life care exists, and why such a large potential cost savings can be anticipated from medical aid in dying in Canada. Therefore, our response should be to transform end-of-life care.

Canada continues to offer a hospital-centric care system to those who are dying. A recent study comparing Canada with other developed countries found that $52.1 \%$ of Canadians with cancer die in hospital - the highest rate of the seven countries studied, and a far cry from the rates in the United States and the Netherlands (22.2\% and $29.4 \%$, respectively). ${ }^{6}$ As a result, the mean costs per decedent in the last 180 days of life were the highest in Canada, about double the cost in the Netherlands or England. My colleagues and I have shown that fewer than one in five Ontario residents will receive a physician home visit in their last year of life and, before death, only one in three home care recipients will receive an endof-life designation that is associated with palliative care delivery. ${ }^{7}$ We have also shown that end-of-life costs are fairly stable in the last year of life until the last 120 days, at which point acute care costs (and not community care costs) rise steeply. ${ }^{8}$ This picture is concordant with the current shortfall of community supports in Canada for those who are dying, and it is why the federal government has promised $\$ 3$ billion in new Health Accord transfers for home and palliative care. ${ }^{9}$ This investment aims to enable frail and dying

\section{KEY POINTS}

- Canada continues to offer inadequate, costly and hospitalcentric care to those who are dying, because a systematic and coordinated palliative approach to end-of-life care is lacking in many jurisdictions.

- Alleviation of suffering is the common ground that proponents and opponents of medical aid in dying can stand on.

- What matters most is increasing the reach of palliative care to prevent undue suffering and the excessive use of medical aid in dying.

patients to remain in the community - a prevalent and strong desire for most.

Trachtenberg and Manns ${ }^{4}$ explicitly state that they do not suggest that medical aid in dying be used to cut health care costs. The very notion of costing end-of-life care and estimating savings with medical aid in dying is a bitter ethical quandary for some. Yet in a system that has finite resources, such costing work can be helpful. We must recognize, however, that high end-of-life costs are often an unintended symptom of our failure to prevent undue suffering, the very thing that patients will seek to avoid by choosing medical aid in dying. Whether one supports medical aid in dying or not, it is clear that end-of-life care discussions need to shift toward how we can improve palliative care. New investments in care should aim to reduce the inadequate match of services to needs, reduce unnecessary emergency department visits and hospital admissions, and, ultimately, reduce suffering at the end of life.

We also need better surveillance data. Trachtenberg and Manns ${ }^{4}$ diligently examined many assumptions through sensitivity analyses, including what proportion of deaths will occur through medical aid in dying (1\%-4\%) and the length of life shortened (one week to one month). Their models, however, are based on best estimates because surveillance data are lacking. A coordinated and systematic national surveillance system is needed to enable ongoing evaluation and research to determine to what extent, to what level of appropriateness and to what consequence medical aid in dying is being delivered. Nevertheless, the variability in the estimates in the linked study speaks to uncertainty as to who will seek out medical aid in dying, and in what period before death. Policy-makers and physicians should focus on the opportu- 
nity that this uncertainty affords. The difference between $1 \%$ and $4 \%$ of all deaths represents a grey zone of about 8000 Canadians annually who may choose to end their life. Whereas some patients who seek medical aid in dying are resolute in their choice, the choices of others may reflect the failure of our health care system to provide effective palliative care.

Patients may request medical aid in dying throughout different points of their dying journey - from shortly after they receive a shocking diagnosis of a terminal illness to when they are burdened with distressing symptoms close to death. Instead of simply referring to medical aid in dying services, we need to thoroughly explore the desires behind the request. The proper introduction of palliative care supports may alleviate the desire for medical aid in dying, not simply by relieving symptoms, but also by reducing the fear and uncertainty in the dying process, and the all-too-common fear of burdening family members with a dying process that is inadequately supported by health care services. Palliative care can address these concerns and help to make a good death part of a good life lived.

Alleviating suffering is the common ground that proponents and opponents of medical aid in dying can stand on. We should quickly move past counting dollars saved from medical aid in dying, and count instead the days of unbearable suffering that result from missed opportunities to provide palliative care. We should strive to save on suffering and to invest more in its reduction, which may in turn reduce requests for medical aid in dying. A continuing movement, pioneered by the World Health Organization, seeks to bring a public health approach to palliative care. ${ }^{10}$ This means introducing appropriate policies, education and surveillance to ensure the availability of care throughout all levels of society.
What matters most is that we address society's failure to provide adequate care for the dying.

\section{References}

1. An act to amend the Criminal Code and to make related amendments to other acts (medical assistance in dying), 2016, Bill C-14. Assented June 17, 2016 (42nd Parliament, 1st session). Available: http://laws-lois.justice.gc.ca/PDF/2016_3. pdf (accessed 2016 Nov. 5).

2. Payne E. Faith-based hospitals' right to refuse assisted death will be challenged, Joyal says. Ottawa Citizen 2016 Oct. 22. Available: http://ottawacitizen. com/news/local-news/faith-based-hospitals-right-to-refuse-assisted-death-will -be-challenged-joyal-says (accessed 2016 Nov. 5).

3. Results of the CMA member survey on medical assistance in dying, June 2016. 2016 June 28. Ottawa: Canadian Medical Association; 2016. Available: www.cma.ca/ Assets/assets-library/document/en/advocacy/maid-survey-summary-june-2016 -english.pdf (accessed 2016 Nov. 5).

4. Trachtenberg AJ, Manns B. Cost analysis of medical assistance in dying in Canada. CMAJ 2017 January 23;189:E101-5. doi: 10.1503/cmaj.160650.

5. Astles P, Prada G, Verbeeten D. Understanding health and social services for seniors in Canada. Ottawa: The Conference Board of Canada; 2015.

6. Bekelman JE, Halpern SD, Blankart CR, et al. International Consortium for Endof-Life Research (ICELR). Comparison of site of death, health care utilization, and hospital expenditures for patients dying with cancer in 7 developed countries. JAMA 2016;315:272-83.

7. Tanuseputro P, Budhwani S, Bai YQ, et al. Palliative care delivery across health sectors: a population-level observational study. Palliat Med 2016 June 16. [Epub ahead of print] doi:10.1177/0269216316653524.

8. Tanuseputro P, Wodchis WP, Fowler R, et al. The health care cost of dying: a population-based retrospective cohort study of the last year of life in Ontario, Canada. PLoS One 2015;10:e0121759.

9. Lambert S. Trudeau promises \$3-billion investment in home care, mental health. Globe and Mail [Toronto] 2015 Sept. 30. Available: www.theglobeandmail.com/ news/politics/trudeau-promises-3-billion-investment-inhome-care-mental-health/ article26597132 (accessed 2016 Nov. 5).

10. Stjernswärd J, Foley KM, Ferris FD. The public health strategy for palliative care. J Pain Symptom Manage 2007;33:486-93.

\section{Competing interests: None declared.}

This article was solicited and has not been peer reviewed.

Affiliations: Bruyère Research Institute; Clinical Epidemiology Program, Ottawa Hospital Research Institute, Ottawa, Ont.

Acknowledgements: The author greatly thanks Denise Marshall, Doug Manuel, Amy Hsu and Carol Bennett for reviewing this commentary and providing helpful insights.
Correspondence to: Peter Tanuseputro, peter.tanuseputro@mail. utoronto.ca

Editor's note: The author of this commentary (P.T.) supplied data that informed the findings of the linked research paper. P.T. was acknowledged for supplying data by the authors of the research paper, but he did not contribute to analysis of the data. 